\title{
9. The Indigenous hybrid economy: Can the NATSISS adequately recognise difference?
}

\author{
Jon Altman, Nicholas Biddle and Geoff Buchanan
}

In today's Australia, hunting is an unusual form of productive activity, but for many Indigenous Australians it represents one continuity with the precolonial hunter-gatherer mode of production. The settler and state colonisation of Australia has generated a remarkable diversity of available livelihood options and hunting remains one form.

Fig. 9.1 Butchered remains of a feral water buffalo near Mumeka outstation, Arnhem Land

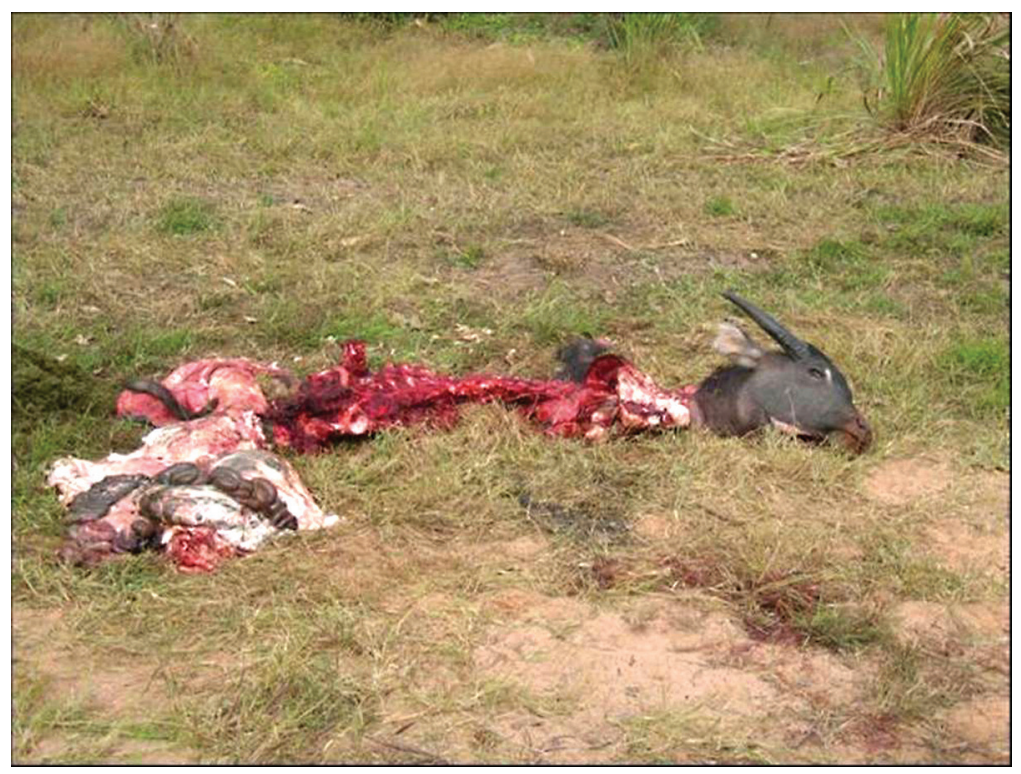

Photo: Jon Altman

We begin with two graphic illustrations of difference because part of the rationale for the NATSISS is to document Indigenous difference as well as diversity. The butchered carcass of a feral water buffalo shown in Fig. 9.1 was located on the side of the main road between Maningrida and Darwin near an outstation called Mumeka, in remote western Arnhem Land at about the time the 2008 NATSISS was in the field. The skilful butchering indicated that the Kuninjku hunters had taken several hundred kilograms of meat for domestic consumption. They had 
also removed one individual of an introduced species that poses a significant ecological threat to Arnhem Land. The water buffalo (Bubalis bubalis) is a feral animal responsible for much damage of wetlands in the surrounding Indigenous Protected Area, which is of high conservation value. Feral buffalo also contribute to global carbon emissions - the removal of this buffalo reduced CO2 equivalent greenhouse gases by an estimated one tonne per annum (Garnett 2010). So we ask rhetorically, can the National Aboriginal and Torres Strait Islander Social Survey (NATSISS) statistically capture and adequately interpret this hunting event and its productive outcomes? Can NATSISS record distinctive Indigenous activity such as hunting, fishing or gathering of wildlife or cultural production and thus document its economic significance Australia wide?

The map shown in Fig. 9.2 uses information from a number of sources to summarise Indigenous land holdings today and the distribution of what the Australian Bureau of Statistics (ABS) terms discrete Indigenous communities, although most of the larger communities also have non-Indigenous residents. This Indigenous estate covered about 1.7 million square kilometres (in 2010), 99 per cent of which is in very remote Australia. The over 1000 depicted communities have a total population estimated in 2006 of less than $100000-$ about 20 per cent of the estimated national Indigenous resident population. One would not expect people living in these small communities - especially when located on Indigenous-owned land remote from centres of industry and commerce - to live like other Australians. So the question is raised, how do people in such circumstances live and what can the NATSISS tell us about their livelihoods?

In this chapter we begin by defining what we mean by the customary sector and how we see it as part of contemporary Indigenous hybrid economies. We then present a critical discussion of the effectiveness of the NATSISS as a survey instrument to collect information on the customary sector. This includes a brief historical discussion going back nearly 20 years to when a national survey of Indigenous Australians was first mooted; followed by a description and analysis of how data on customary activity were conceptualised, categorised and collected in NATSISS 2008. We especially focus here on why some forms of productive activity are categorised as cultural rather than economic; and why information on the customary has such poor visibility in standard NATSISS 2008 outputs. 
Fig. 9.2 Map of the Indigenous estate and discrete Indigenous communities, 2010

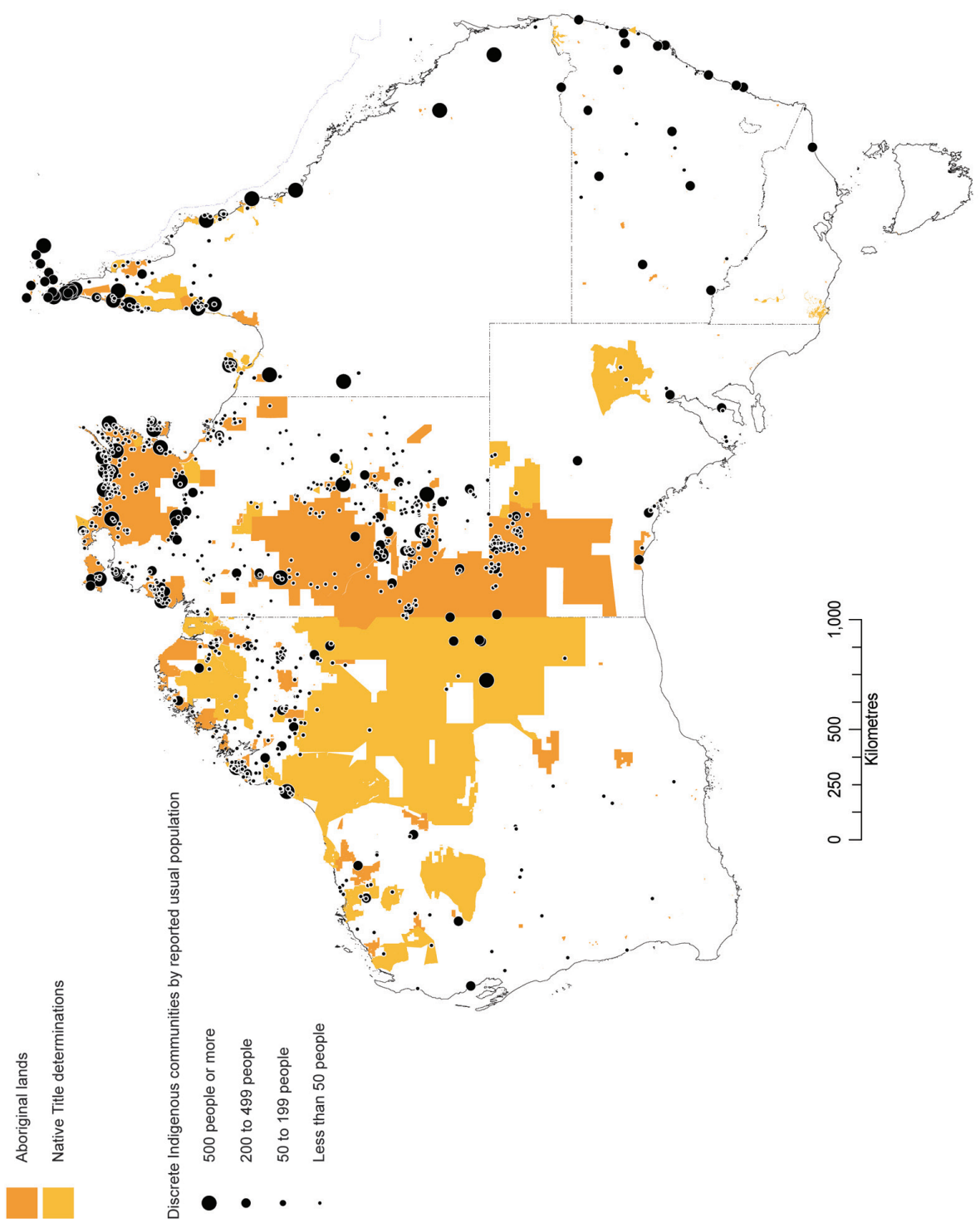

Source: Courtesy of Altman and Hughes, CAEPR 
Next we look at the data available in NATSISS 2008 and provide some estimate of the significance of these activities. In accord with a recommendation we made in 2006 (Altman, Buchanan and Biddle 2006: 150) information on wildlife harvesting ${ }^{1}$ was collected for all Indigenous Australians in 2008 and not just for those in Community Areas. We are now able to investigate how harvesting and cultural production vary according to place of residence, age, gender, employment status, use of Aboriginal languages, and other variables. We are also able to statistically link available information to some very pertinent policy questions about the factors and motivations that might influence participation in the customary sector.

In the final section we discuss some significant policy and political implications of our findings in two senses: for Indigenous affairs policy making in general and for statistical collection policy making in particular. We ponder the dialectical relationship between the two at a time when policy making is supposedly influenced by evidence and yet the policy community and public discourse largely ignores the evidence. We lament the moral hazard that this presents both to those within the ABS and social scientists who are actually committed to improved data collection and analysis to inform policy making. We conclude by returning to our prefacing vignettes and asking how helpful NATSISS 2008 has been in answering our opening questions.

\section{The customary sector of Indigenous hybrid economies}

We are interested in what we term here the 'customary sector' of the Indigenous hybrid economy. By this we mean forms of productive activity, whether for domestic use or for market exchange, that are dependent on Aboriginal custom. In using the term 'customary' we are not suggesting that there are forms of productive activity today that are either pre-colonial or magically divorced from neoliberal globalisation. What we seek to highlight is that there are forms of production that do not fit neatly into the categories of public or private sector or state or market sector because they might be informal or un-marketed. In previous work (see Altman, Buchanan and Biddle 2006) we have depicted the customary sector as a part of hybrid economies, with the customary sector articulating with the state and market sectors. In the example above of the feral buffalo - it was shot with a gun, butchered with a knife, and transported with

\footnotetext{
1 In recent years it has become increasingly common to use the term 'harvesting' as a gloss for hunting, fishing and gathering while overlooking its agricultural connotations. So we would like to emphasise, cognisant of Nadasdy's (2011) critique of such practice, that we are continuing this practice here for comparative purposes only and not to infer anything agricultural in hunting, fishing and gathering practices recorded in NATSISS, Likewise we could include the term 'wildlife' every time we refer to harvesting, but have chosen not to.
} 
a vehicle all of which were bought from the market sector by the hunters using cash income from the state sector and guided primarily by social relations of production, distribution and consumption based on custom and unique to the customary sector (Altman 2005). Arguably, just as there is no 'pure' market or state sector in the hybrid economy, there is no 'pure' customary sector, but rather sectoral overlaps between customary, state and market sectors represented diagrammatically in a three-circle Venn diagram in the hybrid economy model (Altman, Buchanan and Biddle 2006).

Our earlier analysis of the 2002 NATSISS focused on the customary sector in remote Australia. This was not because we did not expect it to occur in non-remote Australia, but rather because wildlife harvesting data then were only collected for Community Areas that replicated by-and-large the discrete Indigenous communities in Fig. 9.2. Intuitively though, one would expect the customary sector to be more significant in remote regions because Aboriginal land ownership and access to natural resources are predominantly in very remote Australia. Indigenous residence on this remote land also reduces opportunity for standard commercial or labour market engagement and so potentially makes the customary more important. We will exploit wider coverage of the customary sector in the 2008 NATSISS to test whether this is empirically the case.

We should emphasise that our focus on the customary is not driven by some academic interest in the esoteric. In our view, a more inclusive and realistic representation of Aboriginal life worlds and wellbeing includes the customary sector of what are unusual hybrid economies in many contexts. It should not be overlooked that activities like harvesting or the production of elements of high or popular culture require effort, might be remunerated, and are often productive in tangible as well as intangible ways.

\section{The national survey and the customary sector}

For just on 20 years now scholars from the Centre for Aboriginal Economic Policy Research (CAEPR) have engaged with the ABS and regularly published research findings highlighting the need for the national survey of Indigenous Australians to collect information about difference as well as similarities in Indigenous economic forms. In 1992, before the first National Aboriginal and Torres Strait Islander Survey (NATSIS) 1994, Altman and Allen (1992: 138) highlighted the need for the survey to broaden the notion of employment to include productive activity in what was then termed the informal economy and what we now call the customary sector. This recommendation was responding to the policy imperative of the time to deliver employment and income equality between Aboriginal and other Australians by the year 2000. Altman and 
Allen emphasised that work in the informal economy generated employment and income that should not be discounted just because official measures of employment and income status relied on standard social indicators. The ABS responded by positively categorising such work as 'employment and income' but then rather perversely relegated it to the sub-category 'voluntary work'. Researchers were critical of this (see Smith and Roach 1996).

In the 2002 NATSISS, the ABS changed tack and included questions about harvesting, cultural production and the ability to meet cultural obligations while in employment, under the broad category 'Culture'. It is far from clear why this is the case except that some Aboriginal people today do use the term 'cultural economy'. We were critical of this classification but principally for practical reasons: it is likely that responses to economic questions subsumed under the category 'culture' might understate their economic significance (Altman, Buchanan and Biddle 2006). Unfortunately, our views were ignored and in the 2008 NATSISS such materially productive activity continues to be categorised as cultural rather than economic.

Theoretically, we are not averse to the argument made famous by the economic historian Karl Polanyi (1944) that the economy is, as a rule, embedded in social relationships. Carrier (1997: 25) notes that Marx, Weber, Durkheim, Mauss and Polanyi each viewed the economy (in particular the capitalist/market economy) as a social and cultural construction. Along similar theoretical lines, Escobar (1995) analyses economics as culture based on the view that the economy is 'above all a cultural production' (Escobar 1995: 59). But if the ABS shares this view, then all economic questions should be couched as cultural for Indigenous and non-Indigenous Australians. Instead this differential treatment appears to suggest the opposite: that the dominant ideology of the western market mentality - as outlined and critiqued by Polanyi (1944) and Escobar (1995, 2008) (and others, e.g. Block 1990; Carrier 1997; Foucault 1994, 2008; GibsonGraham 2006a 2006b; Rose 1999; Scott 1998; Throsby 2001) - is acquiesced to by the ABS as if it is unproblematic to those with differing world views. As Waring (1988: 3) notes in relation to the official collection of economic statistics, "the question of what entails "economic activity" revolves around the question of value'. In its acquiescence to the dominant ideology, the ABS adheres to a value system within which a non-capitalist economic reality such as the customary sector is either ignored or is 'seen as opposite, subordinate, or complementary to capitalism, never as economic practices in their own right or as sources of difference' (Escobar 2008: 74). ${ }^{2}$ And so an Indigenous form

2 An example of such market-centred ideology is provided by Johns (2011: 206) who states that '[t]he Aboriginal economy is an internal, redistributive economy that creates no value'. For Johns 'the (regulated) market economy is the principal determinant of opportunities' (2011:41) and 'culture, where it conflicts with adjustment to the market economy, [is] a problem' (2011: 53). 
of productive economic activity is reclassified in accord with the dominant discourse of Australian capitalism to marginalise what may be non-mainstream forms of Indigenous comparative advantage, speciality and distinctiveness - not to mention identity.

The problem here is far from just semantic. Part of the project of scholars has been to emphasise to the ABS that the NATSISS currently provides the only official survey instrument that could capture economic reality across Indigenous Australia. That reality includes Indigenous participation not just in the customary non-market sector, but also in productive activities that occur where the customary inter-links with the market and state sectors of local economies. These recommendations for accurate measurement of non-standard forms of Indigenous productive activity have been implemented in a fashion that has reduced the possibilities for time series comparison and/or leaves the logical basis for change unexplained.

Let us demonstrate this with changes that occurred between the 2002 and 2008 NATSISS concretely. We criticised the capacity of the 2002 NATSISS to generate useful data on the customary sector on the following grounds which we summarise here:

- coverage was incomplete, focusing exclusively on Community Areas in remote Australia

- gathering of bush foods was not included as an activity

- land and sea management using Indigenous ecological knowledge was ignored as a customary activity

- the focus was on group activity rather than individual activity, suggesting perhaps that real jobs were viewed as individual and economic and customary work as collective and cultural

- coverage was seasonally limited to activities conducted over the previous three months

- there was lack of comparability with the 1994 NATSIS

- participation in the customary sector was not integrated with other economic activities.

In 2008 a number of questions were asked under 'Cultural Participation.' Importantly, coverage was expanded to include all Indigenous people surveyed regardless of whether they lived in remote or non-remote Australia. Although we don't make use of the data in this paper, the questions were also included in the new child component of the survey (for those over the age of three years at least). The following are summaries of the key 2008 NATSISS questions that we turn to in the next section: 
- Q01CULP: 'In the last 12 months have you or your child been involved in any of the following Aboriginal and Torres Strait Islander cultural activities or ceremonies? (from a prompt list)

- Q03CULP: 'Including activities done as part of your job, have you or your child done any of the following activities in the last 12 months? (from a prompt list including gathered wild plants/berries which was missing in 2002)

- Q04CULP: 'In the last 12 months for what reason did you...? (from answers to Q03 from a prompt list). ${ }^{3}$

Other questions asked if activities were undertaken with children; about the source of teaching of activities; the self-assessed importance of participating in such activity; about the frequency of activity; and about respondents' ability to participate and barriers to participation.

Arguably the ABS picked up many of our specific recommendations, but then as predicted - because of the changes, the possibility for comparison with the 2002 NATSISS was lost. And some questions changed from recording outcomes in 2002 ('Were you paid for cultural production?) to motivation (from a prompt list of possible reasons for participating, with 'Get money as income' as the fourth option).

Our most strident criticism remains though. The ABS in the 2008 NATSISS (as in previous surveys) has consciously or unconsciously ignored the potential economic importance of participating in the customary economy, reducing our national capacity to document what we have previously termed the real 'real' economy in remote Australia (Altman, Buchanan and Biddle 2006) in contrast to the 'real' market economy as depicted by Pearson (2009) and Johns (2011). As noted above, this was identified as problematic nearly 20 years ago and it is even more so now. This is partly because with Commonwealth native title legislation passed in 1993 the Indigenous estate has grown significantly, now covering a much larger part of the Australian continent as shown in Fig. 9.2. This is land held invariably under various forms of limited or restricted common property regimes where one might expect a different form of economy from the individuated leasehold or private property regimes that cover much of the balance of Australia (reserved public lands aside).

In our view there is great potential for a special survey like the NATSISS, to inform the Australian public and policy makers about the diverse forms of the

3 The potential reasons coded by the ABS are: Food; Own enjoyment/fun; Enjoyment/fun with others; Cultural learning or ceremony; Get money as income; Medicinal; School activity; and Other.

4 A key difference between Johns (2011) and Pearson $(2000,2009)$ is that Pearson explicitly recognises what he calls the 'traditional subsistence economy' as a real economy producing significant value in terms of Aboriginal wellbeing. As footnoted above, Johns (2011) sees no value as being created from what he variously terms a 'mock', 'faux', or 'pretend' Aboriginal economy based on cultural difference. 
economy on the Indigenous estate. It is paradoxical that as the Indigenous land base and alternate forms of economy are expanding, the ABS is publishing less and less data about such diversity. Instead the ABS has focused on the dominant policy approach and rhetoric of the day be it 'Employment Equity by the Year 2000', practical reconciliation or Closing the Gap - all approaches that privilege sameness over diversity and difference.

\section{NATSISS results}

As social scientists we are disappointed that the national survey of Indigenous Australians conceived and intended to explore Indigenous difference and diversity has design faults. We are interested here in economic difference both between Indigenous Australians and between Indigenous Australians and other Australians, but find little that assists us directly. So we are forced to a second best, and examine the data collected under the rubric of 'Culture'.

Despite our reservations about what is available, we find we can interrogate NATSISS 2008 information on aspects of the customary sector of the hybrid economy in both remote and non-remote Australia. We focus on two areas, wildlife harvesting activities and cultural production. Here we use both description and more sophisticated forms of regression analysis from customised calculations from the 2008 NATSISS to search for relationships between variables in a manner that has never been attempted before. This analysis generates both predictable and surprising findings.

Cross-tabulated information on the proportion of the Indigenous population that participated in harvesting and cultural production activities by demographic, geographic and employment characteristics in 2008 is provided in Table 9.1. Across Australia, it is estimated that 60 per cent of the population aged 15 years and over participated in such activities in the past 12 months. Of the harvesting activities, fishing is more prevalent than hunting which in turn is more prevalent than gathering wild plants/berries. With regards to forms of cultural production, art and craft manufacture seems more prevalent than writing or telling a story which is more prevalent than performing any music, dance or theatre. Note that only an unspecified proportion of this cultural production is marketed commercially. 


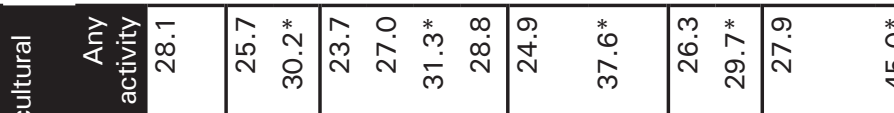

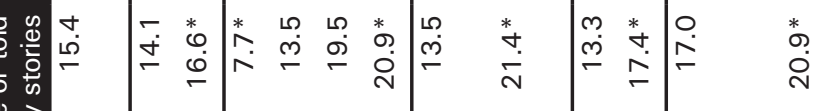

है

8

巳

요

뀽

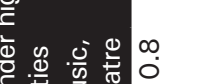

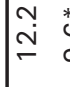

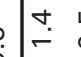

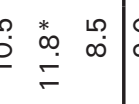

$\stackrel{*}{+}$

กั *

$\stackrel{*}{\text { i }}$

ড়

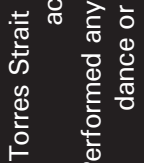

욤

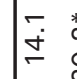

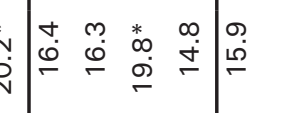

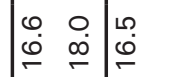

๑

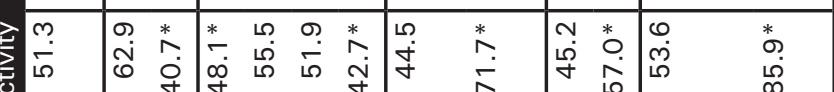

宊

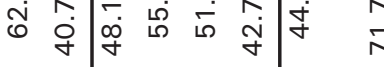

חִ

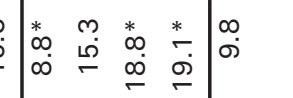

ब्र.

$\underset{\sim}{\stackrel{\sim}{*}}$

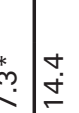

$\stackrel{\mathscr{\infty}}{\mathscr{L}} \quad$ 을

(1)

$+$

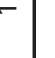

$\stackrel{*}{\mathfrak{m}}$

(6)

ลั่

ํ.

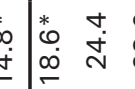

\begin{tabular}{ccc}
0 & $*$ \\
$\stackrel{\sim}{N}$ & 0 \\
\hdashline & 0
\end{tabular}

$\stackrel{\circ}{\stackrel{\circ}{\mathfrak{V}}}$

กิ่

\begin{tabular}{ll}
$\circ$ & $*$ \\
\hdashline & $\circ$ \\
\hdashline & $\stackrel{\circ}{\circ}$ \\
\hdashline
\end{tabular}

$\infty$
$\dot{y}$

궁․

*

ז.

Or

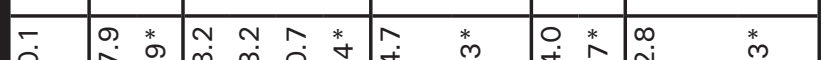

¿

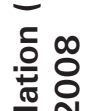

安

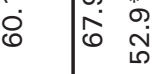

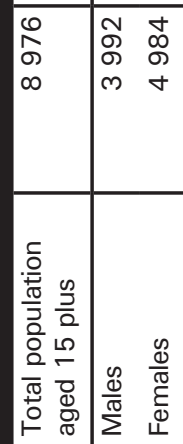

ำ $\frac{\pi}{\frac{1}{2}}$

里

बำ

을

ฮ่

光 $\frac{\pi}{\frac{0}{0}}$

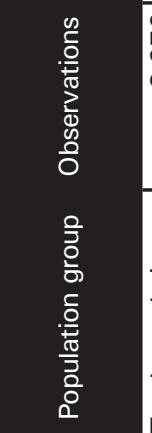

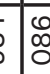

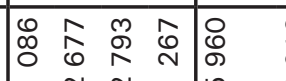

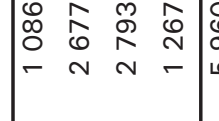

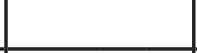

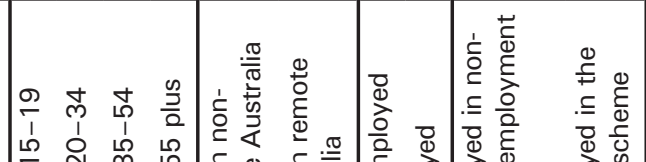

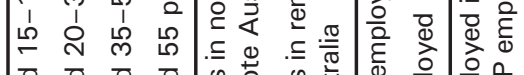

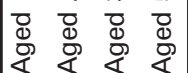

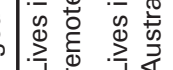


Focusing just on results that are significant at the $5 \%$ level of significance (marked with a single asterisk (*) in Table 9.1) we make the following observations:

- Indigenous people who live in remote Australia are significantly more likely to take part in wildlife harvesting and cultural production

- the employed (inclusive of those employed through the Commonweath Government's Community Development Employment Projects (CDEP) program that had been phased out in urban Australia at the time of the 2008 NATSISS and is being radically reformed in remote Australia) are more likely to participate in all activities than those not employed (except in art and craft manufacture)

- those in CDEP employment, which is often part-time, are more likely to participate in all activities than those in non-CDEP employment

- the age-grade data are somewhat inconclusive but predictable - that is, the old do less harvesting but more story telling than the young

- fewer females participate in harvesting than males, but more females participate in cultural production than males.

Overall, over 76 per cent of those in remote Australia aged 15 years and over do some harvesting or cultural production, 72 per cent participate in harvesting and 38 per cent participate in cultural production. It is hard to compare wildlife harvesting in 2002 with 2008 because in the former the question was only asked in Community Areas where the number (hunted or fished in a group) appears higher but cannot be validly compared. The figures for cultural production which can be compared appear higher in both remote and non-remote areas in 2008. The important question that cannot be answered using NATSISS is how productive were these activities.

Results for the regression analysis using the probability of participating in harvesting activities are presented in Table 9.2. For the analysis presented in Table 9.2 and Table 9.3, the probability of the base case person is given in the second last row of the table and the characteristics in the notes under the table. For example, the predicted probability for those living in remote Australia is compared to an otherwise identical person living in non-remote Australia. Four separate estimates are given in each of the tables. The first two are based on estimations for all of Australia with Model 1 including mainly demographic, geographic and education attainment variables. The second model also includes these variables but, in addition, has variables for education participation, employment and income. The reason for estimating two separate models is that there is a strong possibility that current participation in harvesting activities determines education participation, employment or income, rather than vice versa. It is important to test whether the results for the other variables differ with and without the inclusion of these potentially endogenous variables. Results are 
presented as marginal effects or the difference in the probability of participating compared to the base case person (whilst holding all else constant). Marginal effects are presented for all variables regardless of their significance; however, variables that were significant at the $1 \%, 5 \%$ and $10 \%$ levels of significance are differentiated with asterisks.

Focusing only on statistically significant findings we find that:

- those who live in remote Australia were significantly more likely to participate in harvesting (as in Table 9.1)

- females were significantly less likely to participate in wildlife harvesting, with the difference greatest in non-remote Australia (or alternately, men are more likely to be harvesters)

- those aged 55 years and over were less likely to participate in harvesting activities. However, this was mainly in non-remote as opposed to remote Australia. In remote Australia, those aged 15-19 years were significantly more likely to participate than the base case (i.e. those aged 20-34 years)

- recognising homelands was positively associated with harvesting activities and currently living in a homeland had an extra positive association

- differences in high school education were not associated with participation in harvesting activities. However, those who had completed post-school qualifications had a significantly higher level of participation

- those who spoke an Indigenous language were more likely to harvest than those who did not

- those employed in the CDEP program were significantly and substantially more likely to participate in harvesting activities. It is important to note that this result holds after controlling for remoteness, age and whether or not the person was employed part-time (which by itself, was not significant).

Apart from the findings for education (which were difficult to predict a priori) these results are all predictable and to be expected bearing in mind the usual proviso that we are measuring relationships based on theorised not measured causality (see Ziliak and McCloskey 2007). Issues of subjective motivation aside (these will be explored below) we know that people are more likely to harvest because they have access to lands and seas and resources, but they may also harvest because they have to when living in such situations for food security. People are more likely to hunt when they live on homelands, but they may also live on homelands so that they can hunt. 
Table 9.2 Factors associated with the probability of participating in harvesting activities in the last 12 months, by remoteness classification, Australia, 2008

\begin{tabular}{|c|c|c|c|c|}
\hline \multirow[b]{2}{*}{ Explanatory variables } & \multicolumn{2}{|c|}{ Australia } & \multirow{2}{*}{$\begin{array}{c}\text { Non-remote } \\
\text { Model } 2\end{array}$} & \multirow{2}{*}{$\begin{array}{l}\text { Remote } \\
\text { Model } 2\end{array}$} \\
\hline & Model 1 & Model 2 & & \\
\hline Lives in remote Australia & $0.178 * * *$ & $0.158 * * *$ & & \\
\hline Female & $-0.215^{* * *}$ & $-0.216 * * *$ & $-0.238 * * *$ & $-0.141^{* * *}$ \\
\hline Aged $15-19$ & 0.029 & 0.032 & 0.024 & $0.138 *$ \\
\hline Aged $35-54$ & $-0.050 * *$ & $-0.047^{*}$ & -0.045 & -0.039 \\
\hline Aged 55 plus & $-0.110 * * *$ & $-0.084^{*}$ & $-0.110 * *$ & 0.007 \\
\hline Parent or guardian of child aged $0-14$ years & 0.038 & $0.063^{* *}$ & $0.071^{*}$ & $0.099 * * *$ \\
\hline Married & $0.040 *$ & 0.016 & 0.023 & 0.000 \\
\hline Additional person living in the household & 0.001 & -0.003 & -0.016 & $0.021 * * *$ \\
\hline Speaks an Indigenous language & $0.224 * * *]$ & $0.229 * * *$ & $0.209 * * *$ & $0.241 * * *$ \\
\hline Recognises an area as homelands or traditional country & $0.111^{* * *}$ & $0.102 * * *$ & $0.083^{* *}$ & $0.190 * * *$ \\
\hline Currently lives in homelands or traditional country & $0.101 * * *$ & $0.108 * * *$ & $0.152 * * *$ & -0.010 \\
\hline Has a profound or severe core-activity limitation & -0.013 & 0.018 & 0.023 & -0.028 \\
\hline Completed Year 10 or 11 & 0.008 & -0.003 & -0.011 & 0.037 \\
\hline Completed Year 9 or less & -0.026 & -0.007 & -0.013 & 0.026 \\
\hline Has a degree or higher & $0.096 * *$ & $0.108 * *$ & $0.104^{* *}$ & 0.187 \\
\hline Has an other non-school qualification & $0.061 * *$ & $0.058 * *$ & $0.058 * *$ & 0.072 \\
\hline Cannot access a motor vehicle whenever needed & $-0.045^{*}$ & -0.047 & -0.046 & -0.065 \\
\hline Is currently a student & & 0.000 & 0.027 & $-0.176 * *$ \\
\hline Is currently a part-time (as opposed to full-time) student & & 0.013 & -0.007 & 0.147 \\
\hline Not in the labour force & & -0.028 & -0.034 & 0.034 \\
\hline Unemployed & & 0.031 & 0.025 & 0.104 \\
\hline Employed in the CDEP scheme & & $0.169 * *$ & $0.277^{* *}$ & $0.172^{* *}$ \\
\hline Employed part-time & & 0.031 & 0.039 & -0.015 \\
\hline Receives a government pension & & 0.000 & 0.014 & $-0.101 * *$ \\
\hline Household equivalised income in the bottom decile & & -0.064 & -0.057 & -0.094 \\
\hline Household equivalised income in the 2 nd-3rd decile & & -0.028 & -0.052 & 0.044 \\
\hline Household equivalised income in the 7 th-10th decile & & -0.018 & -0.030 & 0.023 \\
\hline Probability of the base case & 0.446 & 0.466 & 0.480 & 0.490 \\
\hline Pseudo R-Squared & 0.1320 & 0.1312 & 0.0814 & 0.1366 \\
\hline Number of observations & 7562 & 6169 & 4159 & 2010 \\
\hline
\end{tabular}

Notes: The base case person: lives in non-remote Australia; is aged 20-34; is not a parent or guardian and is not married; lives in a four-person household; does not speak an Indigenous language; does not recognise an area as a homeland or traditional country; does not have a profound or severe core-activity restriction; has completed Year 12 but does not have a post-school qualification; can access a motor vehicle whenever needed; is not a student; is employed full-time but not in the CDEP program; does not receive a government pension; and has a household equivalised income in the 4 th to 6 th decile (based on the non-Indigenous income distribution).

*** Marginal effect for which the coefficient is statistically significant at the $1 \%$ level of significance.

** Marginal effect for which the coefficient is statistically significant at the $5 \%$ level of significance.

* Marginal effect for which the coefficient is statistically significant at the $10 \%$ level of significance.

Source: Customised calculations using the 2008 NATSISS 
Survey Analysis for Indigenous Policy in Australia

Table 9.3 Factors associated with the probability of participating in Aboriginal or Torres Strait Islander cultural activities in the last 12 months, by remoteness classification, Australia, 2008

\begin{tabular}{|c|c|c|c|c|}
\hline \multirow[b]{2}{*}{ Explanatory variables } & \multicolumn{2}{|c|}{ Australia } & \multirow{2}{*}{$\begin{array}{c}\text { Non-remote } \\
\text { Model } 2\end{array}$} & \multirow{2}{*}{$\begin{array}{l}\text { Remote } \\
\text { Model } 2\end{array}$} \\
\hline & Model 1 & Model 2 & & \\
\hline Lives in remote Australia & -0.003 & -0.006 & & \\
\hline Female & $0.024 * * *$ & $0.025 * * *$ & $0.024 * * *$ & $0.033 * *$ \\
\hline Aged 15-19 & $0.030 * *$ & 0.009 & 0.008 & 0.006 \\
\hline Aged $35-54$ & 0.012 & 0.009 & 0.006 & 0.019 \\
\hline Aged 55 plus & 0.009 & $0.022 *$ & 0.012 & $0.066^{* * *}$ \\
\hline Parent or guardian of child aged $0-14$ years & 0.011 & 0.012 & 0.014 & -0.003 \\
\hline Married & -0.009 & -0.007 & -0.006 & -0.008 \\
\hline Additional person living in the household & $0.004 * *$ & 0.003 & 0.003 & $0.007 * * *$ \\
\hline Speaks an Indigenous language & $0.121 * * *$ & $0.110 * * *$ & $0.145 * * *$ & $0.098 * * *$ \\
\hline Recognises an area as homelands or traditional country & $0.156 * * *$ & $0.135 * * *$ & $0.141 * * *$ & $0.087 * * *$ \\
\hline Currently lives in homelands or traditional country & 0.000 & 0.000 & -0.005 & $0.024^{*}$ \\
\hline Has a profound or severe core-activity limitation & $0.029 * *$ & $0.035 * *$ & $0.040 * *$ & 0.012 \\
\hline Completed Year 10 or 11 & $-0.017 * *$ & $-0.013^{*}$ & $-0.014^{*}$ & -0.003 \\
\hline Completed Year 9 or less & -0.010 & -0.010 & -0.007 & -0.014 \\
\hline Has a degree or higher & $0.139 * * *$ & $0.125 * * *$ & $0.121 * * *$ & $0.134 * *$ \\
\hline Has an other non-school qualification & $0.055 * * *$ & $0.044 * * *$ & $0.042 * * *$ & $0.051 * * *$ \\
\hline Cannot access a motor vehicle whenever needed & 0.001 & 0.000 & 0.006 & -0.016 \\
\hline Is currently a student & & $0.077^{* * *}$ & $0.085 * * *$ & 0.055 \\
\hline Is currently a part-time (as opposed to full-time) student & & -0.017 & -0.017 & -0.009 \\
\hline Not in the labour force & & $-0.023 * * *$ & $-0.023 * *$ & -0.030 \\
\hline Unemployed & & -0.005 & -0.009 & 0.001 \\
\hline Employed in the CDEP scheme & & $0.034 * *$ & $0.144 * * *$ & 0.008 \\
\hline Employed part-time & & -0.009 & -0.015 & 0.013 \\
\hline Receives a government pension & & 0.010 & 0.010 & 0.010 \\
\hline Household equivalised income in the bottom decile & & 0.020 & 0.018 & 0.030 \\
\hline Household equivalised income in the 2 nd-3rd decile & & 0.014 & 0.012 & 0.021 \\
\hline Household equivalised income in the 7th-10th decile & & 0.002 & -0.001 & 0.023 \\
\hline Probability of the base case & 0.061 & 0.051 & 0.046 & 0.077 \\
\hline Pseudo R-Squared & 0.1093 & 0.1140 & 0.1297 & 0.0865 \\
\hline Number of observations & 7562 & 6169 & 4159 & 2010 \\
\hline
\end{tabular}

Notes: The base case person: lives in non-remote Australia; is aged 20-34; is not a parent or guardian and is not married; lives in a four-person household; does not speak an Indigenous language; does not recognise an area as a homeland or traditional country; does not have a profound or severe core-activity restriction; has completed Year 12 but does not have a post-school qualification; can access a motor vehicle whenever needed; is not a student; is employed full-time but not in the CDEP program; does not receive a government pension; and has a household equivalised income in the 4th to 6th decile (based on the non-Indigenous income distribution).

*** Marginal effect for which the coefficient is statistically significant at the $1 \%$ level of significance.

** Marginal effect for which the coefficient is statistically significant at the $5 \%$ level of significance.

* Marginal effect for which the coefficient is statistically significant at the $10 \%$ level of significance.

Source: Customised calculations using the 2008 NATSISS 
In Table 9.3 we repeat the above analysis using the probability of participating in cultural production in the last 12 months. It is noteworthy that here there was no significant difference in participating in cultural production between those who lived in remote Australia and those who lived in non-remote Australia. It would appear that it is other characteristics of individuals that were driving the significant differences found here. Key findings (again focusing on the statistically significant) include:

- females were more likely to participate in cultural production than males, which makes intuitive sense because males do more harvesting and time is limited

- in remote Australia, those aged 55 years and over were significantly and substantially more likely to participate than the base case

- there was a very large (and significant) difference between those who speak an Indigenous language and those who do not, suggesting that Indigenous language supports a person's capacity to make art, perform a dance, and/or tell a story

- those who recognise an area as a homeland were significantly more likely to participate in cultural production than those who did not. For those who do recognise a homeland, there was no significant difference between those who lived on their homeland compared to those who did not. This suggests that harvesting benefits more from more intimate connection to country than does cultural production

- having a disability or 'severe core-activity limitation' was associated with a higher level of participation

- having a post-school qualification and in particular having a degree or higher degree was associated with participation in cultural activities

- being a student was also associated with participating in cultural activities

- those who were not in the labour force were less likely to participate than those who were employed. There was no significant difference for those who were unemployed

- there was a small (but significant) difference for Australia as a whole for those who participated in the CDEP program compared to the rest of the employed population. However, this relationship only appears to hold in non-remote as opposed to remote Australia.

In Table 9.4 we explore the particular reasons respondents gave for participating in each of the wildlife harvesting or cultural production activities. Respondents were able to list more than one activity and hence the columns sum to more than 100. In order to help understand the results presented in Table 9.4, it is useful to look at a particular column in detail. Focusing on the first ('any activity') column, the first line shows that 57.8 per cent of those who participated in a 
harvesting or cultural activity did so for food. Reading down, 63.3 per cent reported that they did so for their own enjoyment/fun, 57.3 per cent said they participated in an activity for enjoyment/fun with others and so on.

Key findings from Table 9.4 highlight some significant differences between remote and non-remote Australia:

- people mainly harvest for food, rarely for cash, although harvesting activity is also a source of enjoyment, and social interaction; people are significantly more likely to harvest for food in remote than non-remote Australia

- people in remote regions are significantly more likely to harvest for cultural learning or ceremony, to get money and for medicinal purposes and less likely to harvest for fun

- people engaged in cultural production mainly to learn or engage in ceremony, for their own enjoyment, and for social interaction

- people in remote Australia are significantly more likely to engage in cultural production for cultural learning and to make money and are less likely to do so as a school activity.

Table 9.4 Reasons for participating in selected activities, by remoteness, Australia, 2008

\begin{tabular}{|c|c|c|c|c|}
\hline \multirow[t]{2}{*}{ Activity } & \multicolumn{2}{|c|}{ Any harvesting activity } & \multicolumn{2}{|c|}{$\begin{array}{l}\text { Any Aboriginal or Torres } \\
\text { Strait Islander cultural activity }\end{array}$} \\
\hline & Non-remote & Remote & Non-remote & Remote \\
\hline Food & 60.8 & $90.9 * * *$ & 0.0 & 0.0 \\
\hline Own enjoyment/fun & 67.8 & $57.2 * * *$ & 51.5 & 55.9 \\
\hline Enjoyment/fun with others & 52.2 & 56.0 & 44.7 & 49.1 \\
\hline Cultural learning or ceremony & 14.8 & $34.8 * * *$ & 53.9 & $73.0 * * *$ \\
\hline Get money as income & 1.1 & $3.9 * * *$ & 9.4 & $21.7 * * *$ \\
\hline Medicinal & 6.0 & $11.1 * *$ & 1.2 & 1.5 \\
\hline School activity & 2.9 & 3.3 & 25.3 & $12.1 * * *$ \\
\hline Other & 2.1 & $1.0 * *$ & 6.0 & $2.1 * * *$ \\
\hline
\end{tabular}

*** Differences between remote and non-remote areas significant at the $1 \%$ level of significance.

** Differences between remote and non-remote areas significant at the $5 \%$ level of significance.

${ }^{*}$ Differences between remote and non-remote areas significant at the $10 \%$ level of significance.

Source: Customised calculations from the 2008 NATSISS

One surprising comparative result here is the apparent decline in people paid for cultural production since 2002 (see Altman, Buchanan and Biddle 2006: 146). Whether this decline is factual or illusory is impossible to tell because different questions were asked in 2002 and 2008: in the former year people were asked what the outcome of their cultural production was (i.e. whether or not 
they were (or would be) paid), in the latter the motivation for production was sought (i.e. the reason they participated). This illustrates well the problem when questions are changed from survey to survey.

In an exploratory vein we also sought to explore the relationship between participation in the customary sector and self reported measures of health and wellbeing (see Table 9.5). We do not report our results here in detail in part because causality is especially unclear: Was it participation in harvesting or cultural production activities that was influencing self-assessed health and wellbeing, or is causality in the opposite direction? We also found that there were few cells where results were significant, while differentiating remote from non-remote regions would have made the analysis overly complex. Having undertaken the analysis (that we will report in more detail elsewhere) we note the following statistically significant findings:

- those who had fair or poor health were significantly less likely to participate in at least one of the selected activities than those who had good health

- people with a lot of energy a little or none of the time are significantly less likely to fish, hunt or gather

- if people are full of energy they are more likely to hunt, but if they rarely felt full of life they were significantly less likely to fish, hunt or undertake any harvesting activity and are less likely to be a performer, story teller/author, or artist

- hunters are more likely to be happy, but if one is not calm or peaceful one is less likely to fish or hunt

- if one has high psychological distress as measured by a grouped Kessler (K5) score of psychological stress one is more likely to participate in arts and crafts manufacture or perform any music, dance or theatre

- if in fair or poor health one is significantly less likely to fish or participate in harvesting generally. 


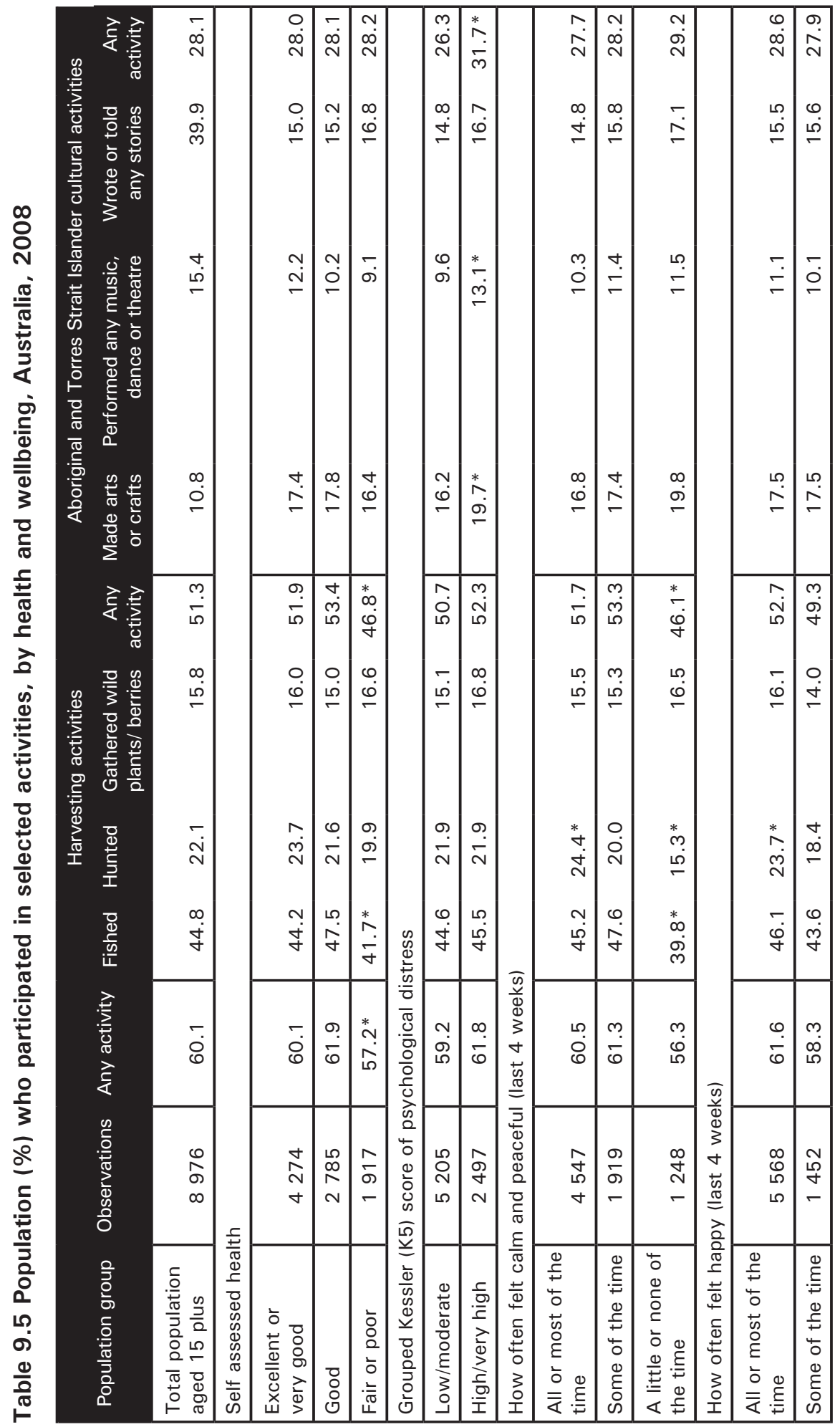


9. The Indigenous hybrid economy: Can the NATSISS adequately recognise difference?

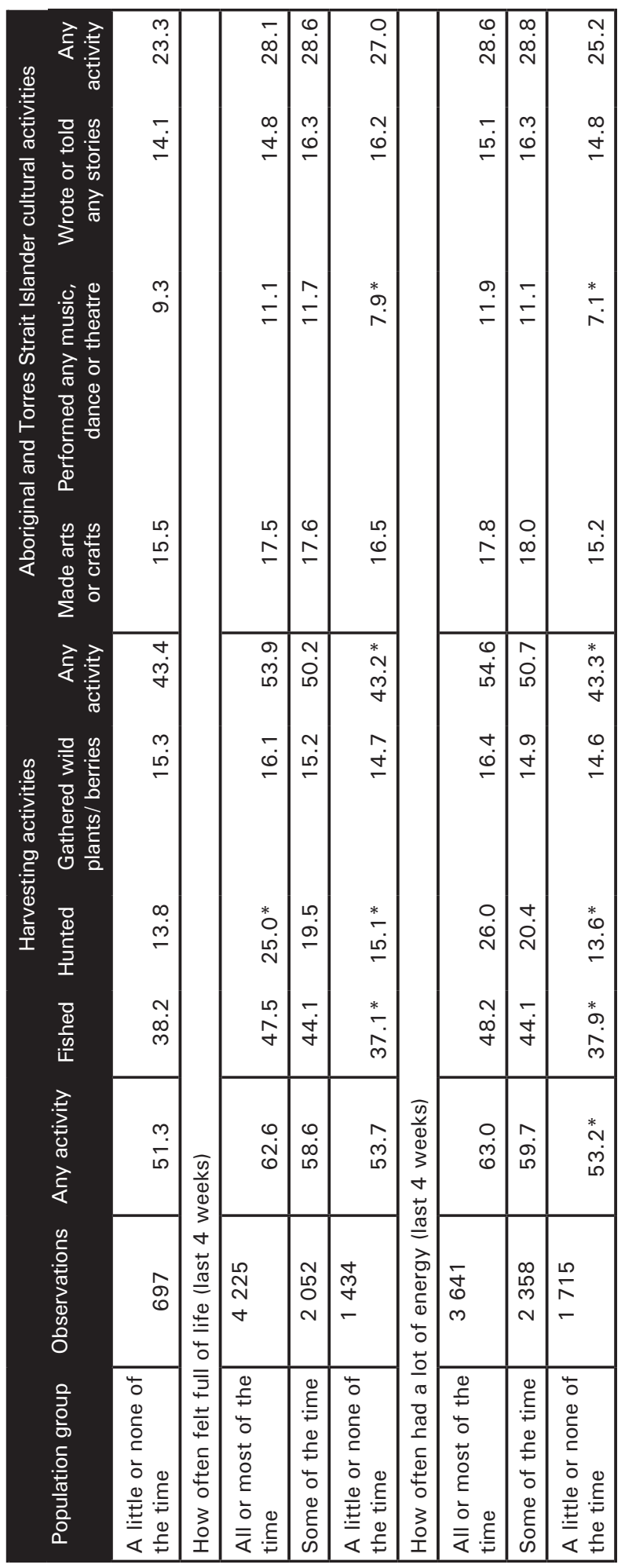

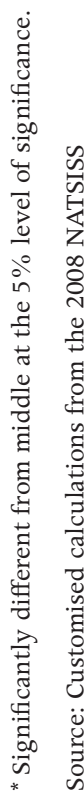




\section{Survey, policy and political implications}

For this volume we have been asked to consider how the data source utilised and analysis undertaken advance social science and inform Indigenous policy making. Turning to the implications of our analysis during an era that is supposed to have evidence-based policy making, not ideology, as its hallmark, clearly our analysis should make a difference to some of the most hotly-debated current issues in Indigenous affairs.

- What form should economic development take?

- What are the prospects for closing the employment gap, especially in remote regions?

- Does the stated aim of policy to standardise economic norms make sense?

- Will closure of education gaps assist people who harvest and engage in cultural production for a livelihood?

- Should the CDEP program be effectively abolished in all but name through radical reform?

- What evidence is there that the current Australian Government focus on larger 'priority communities' and the Northern Territory Government focus on Territory Growth Towns are rational policy approaches?

Further what is the role of the policy-engaged social scientist in making recommendations to the ABS? - realising of course that in the highly politicallycharged environment of Indigenous affairs there will always be diverse and competing statistical interests. Should we, yet again, make constructive recommendations to the $\mathrm{ABS}$ and the wider policy community to gather more economic data that will generate a more robust evidence base to answer important questions such as the above, especially given the likely further growth of the Indigenous estate, the likely further strengthening of property rights on Aboriginal-owned land, and the prospects that the Indigenous population in remote Australia will continue to grow rapidly?

In the absence of other compelling official statistics gathered at the national level, our findings highlight first and foremost that there are statistically significant differences in wildlife harvesting and cultural production between remote and non-remote Australia. These of course are broad categories that combine the fiveregion Accessibility/Remoteness Index of Australia (ARIA) regional geography into just two, a limitation of the publicly available data that has been noted a number of times in this volume. Nevertheless, this finding vindicates our earlier focus on remote Australia and our policy suggestion that the real economy out there includes a robust customary sector. Just how economically significant this sector might be is difficult to say given available statistics. 
Arguably, these findings also suggest that a different broad policy approach might be needed in remote Australia. Putting aside for the moment the national level policy obsession with closing statistical gaps, our findings indicate that Indigenous wellbeing and livelihood could be improved through a combination of harvesting and cultural production to supplement available employment. These productive activities in the customary sector are likely to be significantly higher if participants are employed through CDEP and living at homelands/ outstations and speaking an Indigenous language. These findings do not in themselves suggest that participation in harvesting and cultural production will provide a better outcome than formal employment; only that in the absence of enough mainstream opportunity where people live, it might make sense for policy to support such productive activity - to, in a sense, think outside the market square.

These findings fly in the face of the direction that policy has taken since at least 2005 when then Minister for Indigenous Affairs Amanda Vanstone (2005) traduced outstation residence as living in 'cultural museums' and the Minister for Employment Kevin Andrews began to dismantle the CDEP program; as well as more recent Northern Territory Government reform to prioritise Territory Growth Towns over outstations and to eliminate outstation learning and bilingual education as a viable schooling option. At a higher policy level, an Australian version of the United Nation's Millennium Development Goals was introduced without consultation in early 2008 by then Prime Minister Kevin Rudd under the policy umbrella of Closing the Gap. This national approach was quickly adopted by the Council of Australian Governments (COAG) that in the economic domain has given priority to the goal to halve the gap in employment outcomes between Indigenous and non-Indigenous Australians within a decade. In July 2009, much of this approach was cemented into the COAG National Indigenous Reform Agreement (NIRA) (COAG 2009). This is not the place to critique NIRA in any detail - this exercise has been undertaken elsewhere (see Altman 2010: 268-9). We just note here that NIRA principles and its policy approach are concerning for those in remote Australia whose livelihoods are strongly supported by or reliant upon the customary sector as it aims to:

- centralise people away from homelands

- focus effort on incorporating remote living people into mainstream employment and the market economy

- alter social norms

- skew available resources away from smaller places, and

- render extremely difficult development problems 'technical' and 'statistical' in an abstract manner that ignores the complexity of lived reality that is partially captured by the data we present here (cf. Ferguson 1990). 
In the world of evidence-based policy making is there no information to challenge the hegemonic state approach that promulgates a 21 st century version of the modernisation paradigm as the development solution for all Indigenous Australians? Of course there is: there is the NATSISS. But there are ways in which the data are collected and released that has the potential to marginalise findings that may challenge dominant political and bureaucratic perspectives. These forces are evident in many forms, and we provide three illustrative examples.

First, the 2008 NATSISS was clearly designed and locked in before the change of Australian Government in November 2007 and the launch of the Closing the Gap approach. Its design was probably more influenced by the dominant agenda of 'practical reconciliation', a hallmark of the Howard years. But the way that outputs from the 2008 NATSISS have been made available have clearly conformed to the agenda of the government of the day with priority being given to meeting the needs of the Productivity Commission and its biennial Overcoming Indigenous Disadvantage report that by 2009 was already looking to address COAG targets and headline indicators (Steering Committee for the Review of Government Service Provision (SCRGSP) 2009). In assisting the Productivity Commission meet the directives of the government, the ABS was in no position to give high profile to the customary sector in its media releases or visibility in standard outputs.

Second, the Australian Government has invested in a Closing the Gap Clearinghouse to provide access to information about what works to overcome disadvantage (Australian Institute of Health and Welfare (AIHW)/Australian Institute of Family Studies (AIFS) n.d.). This Clearinghouse has search functions but because it is marshalling evidence that 'relate to the COAG building blocks that underpin the Closing the Gap targets' research on the customary sector is not given high priority either in the general or assessed collections. We did manage to find references to our earlier paper on the 2002 NATSISS and the real 'real' economy. It stated:

\section{The real 'real' economy in remote Australia}

The informal economy, or customary sector, is often ignored in measures of Indigenous employment and income equality. This paper provides an overview of the customary sector and the hybrid economy model and examines the extent to which the 2002 National Aboriginal and Torres Strait Islander Social Survey documents customary activity in remote areas. It focuses on three issues included in the NATSISS that relate to the customary sector: fishing or hunting as a group activity; participation in and payment for cultural activities; and the ability to 
meet cultural responsibilities while in employment. The paper then identifies shortcomings in the survey relating to key customary sector activities and makes recommendations for NATSISS 2008.

It is noteworthy that none of our findings on the significance or potential of the customary sector are reported. Nor does the Clearinghouse engage with our political point that the 'real' economy, a term that is bandied around in political and bureaucratic circles with gay abandon, might actually include the customary sector, especially in remote Australia.

Third, aware that information is not available to measure progress in Closing the Gap, the Australian Government is investing \$46.4 million over four years from 2009-10 to help build a better evidence base against which to measure progress, without entertaining the possibility that there may not be any progress to measure (Australian Government 2011: 17). There is clearly embarrassment that the annual Closing the Gap Prime Minister's Report is unable to actually tell us whether gaps are closing. Even this is contestable, for two of us have actually found that the ABS publication Labour Force Characteristics of Aboriginal and Torres Strait Islander Australians, Estimates from the Labour Force Survey, 2009 (ABS 2010) did assist us with annual official information about whether the employment gap was closing. Applying rigorous significance testing to the data at the national level we found that the gap was actually widening (Altman and Biddle 2010). For making this unpopular evidence-based observation we were chided by the Minister for Employment Participation, Senator the Hon. Mark Arbib who erroneously suggested that the ABS survey we used was too unreliable to make assessments of progress at the national level because of 'high margins of error' (Altman and Biddle 2011). Fortunately the ABS publishes standard errors that we had taken into account in our testing for significance.

All this suggests two things to us. First, the Australian Government is keen on measures that show its gaps are closing, but is less than keen on any suggestion that its strategy is misplaced. Second, while ideology can challenge evidence, it can play a very significant role in influencing what evidence is collected. The historical development of links between government, economy, populations, and statistics outlined by Foucault (1994) under his hypotheses on governmentality highlights the political nature of the production of such statistical evidence. For Foucault:

It was through the development of the science of government that the notion of economy came to be recentered onto that different plane of reality we characterize today as the 'economic', and it was also through this science that it became possible to identify problems specific to 
populations ... And, further, that 'statistics' ... now becomes the major technical factor, or one of the major technical factors, of the unfreezing [deblocage] of the art of government (1994: 215).

For Rose (1999: 33), a scholar heavily influenced by Foucault's writings on governmentality, an abstract space such as 'the Indigenous economy' is not brought into existence by ideology or theory alone, but also through the construction of a statistical apparatus through which this space can be 'inscribed, visualised, tabulated, modeled, calculated ... and so forth'. Rose (1999: 212, 213) describes this as "the fabrication of a "clearing" within which thought and action can occur' and notes that, while abstract, such spaces 'are very material: for they are [inter alia] utilized as a grid to "realize" the real in the form in which it may be thought'. Along these lines we observe that in the context of Closing the Gaps (and its recent predecessors) a massive bureaucratic machinery (including a significant 'statistical apparatus') has been deployed to lend support to the approach being taken by the government of the day an approach where the economic form of the market is the principle grid of economic intelligibility. ${ }^{5}$ As a statistical apparatus of government the NATSISS is being utilised as a grid to realise the real economy of Indigenous Australia, but we maintain our argument (Altman, Buchanan and Biddle 2006) that it fails to realise the real 'real' economy due to its economic neglect and statistical marginalisation of the customary sector.

This leaves the social scientist in a difficult place if the evidence available suggests that either the dominant policy approach is proving unsuccessful or if the somewhat narrow parameters being used to measure economic wellbeing (closing the employment gap) need to be challenged. We realise of course that in the highly politically-charged environment of Indigenous affairs there will always be diverse and competing statistical interests and perspectives, not to mention priorities as outlined above. Nevertheless, yet again we make constructive recommendations to the ABS and wider policy community in relation to gathering economic data that will generate a more robust evidence base to answer such important questions. This is especially important given the likely further growth of the Indigenous estate, the likely further strengthening of property rights on Aboriginal-owned land and the prospects that the Indigenous population in remote Australia will continue to grow.

5 The terminology used here is borrowed from Foucault (2008). In his discussion of the nature of American neo-liberalism Foucault (2008: 243) notes that it involves 'the generalization of the economic form of the market' whereby it becomes 'a principle of intelligibility', an 'analytical schema', or a 'grid of intelligibility'. 
So what prospects for NATSISS 2014? Will the ABS heed our call by, for example:

- classifying customary activity as economic, not just cultural

- collecting data on people working on country in the provision of environmental services utilising Indigenous ecological knowledge as we suggested in 2006

- collecting better data on work density - how often people engaged in activities - so as to assess their significance, ${ }^{6}$ and

- asking some more pertinent questions, not just about motivations but also about outcomes.

What are the prospects of asking some questions in a more open ended manner that might elicit Indigenous responses in accord with Indigenous aspirations and perceptions?

\section{Conclusion}

The argument made in this chapter can be summarised as follows. The NATSISS is one survey instrument that just might allow collection of official statistics that capture Indigenous difference - in this instance, economic difference. But this possibility seems to be circumscribed by the ABS working only within the dominant paradigm of normalisation and Closing the Gap. Perhaps this is not surprising, after all the ABS is a mainstream institution and a part of what might be termed 'the bureaucratic field' (cf. Bourdieu, Wacquant and Farage 1994; also Wacquant 2007). We do not question that the collection of statistics is a highly political project, but we do wonder if the ABS may not be sufficiently open to exploring alternatives.

Despite this, some important data were collected in NATSISS 2008 that we are reporting for the first time. These data show that harvesting and cultural production are significant productive activities, especially in remote Australia. These findings are important as they challenge the wisdom of the current Closing the Gap approach and its attenuated policy reforms to abolish CDEP, refocus

6 For example, Waring (1988: 254) argues that monetary or market value is not the sole criterion for the assessment of work. Work can also be assessed by volume: in terms of the labour power involved in the process (the number of workers) or the work time absorbed (number of hours)'. Alternative conceptions of the economy offer 'us the opportunity for assessing data by way of quality, and quantity, by way of hours and money invested. It invites us to consider interactions. It permits use of all advanced statistical mechanisms' (1988: 254). In this chapter we have touched on the potential of NATSISS to explore correlations and causality between wellbeing (health, happiness, etc.) and Indigenous people's participation in the customary sector. We acknowledge the suggestion by Professor Anne Daly at the NATSISS 2008 CAEPR conference regarding the potential of wellbeing data collected through the NATSISS to provide an outcome measure in the absence of a traditional economic or monetary measure of the contribution of people's participation in the customary sector. 
development effort to larger places, and to incorporate Indigenous people into the mainstream. We believe opportunity exists to collect information to test the success or failure of the current policy framework, but there is also a need to collect data that will allow comparison with alternate possibilities like living on, working on, and painting on country. From a statistical sense, the relatively low amount of variation explained in our models highlights the lack of information in the NATSISS around the determinants of participation in harvesting and cultural production. We suspect that the paucity of geographic information in the available version of the NATSISS has contributed to this lack of statistical power. Surely the role of the NATSISS is to collect and disseminate statistics about sameness as well as difference and, surely, an independent ABS should ensure that such information is collected.

We return to where we began: why are data collected - for academic debates or to provide a glimpse into diverse Aboriginal life worlds? We asked at the outset what can the NATSISS tell us about those who pursue livelihood and wellbeing in a fundamentally different way from the mainstream? The answer, in our view, is not enough.

\section{References}

Altman, J. C. 2005. 'Development options on Aboriginal land: Sustainable Indigenous hybrid economies in the twenty-first century', in L. Taylor, G. Ward, G. Henderson, R. Davis and L. Wallis (eds), The Power of Knowledge, the Resonance of Tradition, Aboriginal Studies Press, Canberra.

2010. 'What future for remote Indigenous Australia?: Economic hybridity and the neoliberal turn', in J. C. Altman and M. Hinkson (eds), Culture Crisis: Anthropology and Politics in Aboriginal Australia, UNSW Press, Sydney.

and Allen, L. M. 1992. 'Aboriginal and Torres Strait Islander participation in the informal economy: Statistical and policy implications', in J. C. Altman (ed.), A National Survey of Indigenous Australians: Options and Implications, CAEPR Research Monograph No. 3, CAEPR, ANU, Canberra.

and Biddle, N. 2010. 'Rudd overpromised on indigenous employment', Crikey, 4 June 2010, viewed 3 March 2011, available at <http://www.crikey. com.au/2010/06/04/closing-the-gap-rudd-overpromised-on-indigenousunemployment/>

and Biddle, N. 2011. 'The massive indigenous employment gap stagnates', Crikey, 1 July 2011, viewed 1 July 2011, available at <http://www.crikey. com.au/2011/01/07/the-massive-indigenous-employment-gap-stagnates/> 
- Buchanan, G. and Biddle, N. 2006. 'The real 'real' economy in remote Australia', in B. Hunter (ed.), Recent Evidence on Indigenous Socioeconomic Outcomes: A Focus on the 2002 NATSISS, CAEPR Research Monograph No. 26, ANU E Press, Canberra.

Australian Bureau of Statistics (ABS) 2010. Labour Force Characteristics of Aboriginal and Torres Strait Islander Australians, Estimates from the Labour Force Survey, 2009, cat. no. 6287.0, ABS, Canberra.

Australian Government 2011. Closing the Gap Prime Minister's Report 2011, viewed 3 March 2011, available at <http://www.fahcsia.gov.au/sa/ indigenous/pubs/closing_the_gap/2011_ctg_pm_report/Documents/2011_ ctg_pm_report.pdf>

Australian Institute of Health and Welfare (AIHW)/Australian Institute of Family Studies (AIFS) n.d. 'Closing the Gap Clearinghouse', viewed 21 November 2011, available at <http://www.aihw.gov.au/closingthegap/>

Block, F. 1990. Postindustrial Possibilities: A Critique of Economic Discourse, University of California Press, Berkley and Los Angeles, California.

Bourdieu, P., Wacquant, L. J. D. and Farage, S. 1994. 'Rethinking the State: genesis and structure of the bureaucratic field', Sociological Theory, 12 (1): $1-18$.

Carrier, J. G. 1997. 'Introduction', in J. G. Carrier (ed.), Meanings of the Market: The Free Market in Western Culture, Berg, Oxford.

Council of Australian Governments (COAG) 2009. National Indigenous Reform Agreement (Closing the Gap), viewed 3 March 2011, available at <http:// www.coag.gov.au/coag_meeting_outcomes/2009-07-02/docs/NIRA_closing_ the_gap.pdf $>$

Escobar, A. 1995. Encountering Development: The Making and Unmaking of the Third World, Princeton University Press, New Jersey.

2008. Territories of Difference: Place, Movements, Life, Redes, Duke University Press, Durham.

Ferguson, J. 1990. The Anti-Politics Machine: 'Development', Depoliticisation and Bureaucratic Power in Lesotho, Cambridge University Press, Cambridge.

Foucault, M. 1994. 'Governmentality', in J. D. Faubion (ed.), Power: Essential Works of Foucault 1954-1984, Volume Three, Penguin Books, London.

2008. The Birth of Biopolitics: Lectures at the College de France 1978-1979, Picador, New York. 
Garnett, S. 2010. 'Climate change and invasive species', in M. Jambrecina (ed.), Kakadu National Park Landscape Symposia Series 2007-2009 Symposium 5: Feral animal management, 3-4 December 2008, Department of Sustainability, Environment, Water, Population and Communities. Viewed 21 November 2011, available at <http://www.environment.gov.au/ssd/publications/ir/568.html>

Gibson-Graham, J. K. 2006a. The End of Capitalism (as we knew it): A Feminist Critique of Political Economy, University of Minnesota Press, Minneapolis.

-2006b. A Postcapitalist Politics, University of Minnesota Press, Minneapolis.

Johns, G. 2011. Aboriginal Self-determination: The Whiteman's Dream, Connor Court Publishing, Ballan, Victoria.

Nadasdy, P. 2011. “We don't harvest animals; we kill them": Agricultural metaphors and the politics of wildlife management in the Yukon', in M. J. Goldman, P. Nadasdy and M. D. Turner, Knowing Nature: Conversations at the Intersection of Political Ecology and Science Studies, University of Chicago Press, Chicago.

Pearson, N. 2000. Our Right to Take Responsibility, Noel Pearson and Associates Pty Ltd, Cairns.

2009. Up from the Mission: Selected Writings, Black Inc, Melbourne.

Polanyi, K. 1944 (2001). The Great Transformation: The Political and Economic Origins of Our Time, Beacon Press, Boston.

Steering Committee for the Review of Government Service Provision (SCRGSP) 2009. Overcoming Indigenous Disadvantage: Key Indicators 2009, Productivity Commission, Melbourne, viewed 3 March 2011, available at <http://www. pc.gov.au/_data/assets/pdf_file/0003/90129/key-indicators-2009.pdf>

Rose, N. 1999. Powers of Freedom: Reframing Political Thought, Cambridge University Press, Cambridge.

Scott, J. C. 1998. Seeing Like A State: How Certain Schemes to Improve the Human Condition Have Failed, Yale University Press, New Haven.

Smith, D. E. and Roach, L. M. 1996. 'Indigenous voluntary work: NATSIS empirical evidence, policy relevance and future data issues', in J. C. Altman and J. Taylor (eds), The 1994 National Aboriginal and Torres Strait Islander Survey: Findings and Future Prospects, CAEPR Research Monograph No. 11, CAEPR, ANU, Canberra.

Throsby, D. 2001. Economics and Culture, Cambridge University Press, Cambridge. 
Vanstone, A. 2005. 'Beyond conspicuous compassion: Indigenous Australians deserve more than good intentions', Address to the Australian and New Zealand School of Government, The Australian National University, Canberra, viewed 21 November 2011, available at <http://epress.anu.edu.au/anzsog/ policy/mobile_devices/ch03.html>

Wacquant, L. 2009. Punishing the Poor: The Neoliberal Government of Social Insecurity, Duke University Press, Durham.

Waring, M. 1988. Counting For Nothing: What Men Value and What Women Are Worth, Allen and Unwin, Wellington.

Ziliak, S. T. and McCloskey, D. N. 2007. The Cult of Statistical Significance: How the Standard Error Costs Us Jobs, Justice, and Lives, University of Michigan Press, Ann Arbor. 